\title{
Antioxidative role of selected herbs against ethanol induced liver injury in rats
}

\author{
Sunil K umar*, Priyanka K umari and Shoma Devi \\ Environmental Toxicological Laboratory, Department of Zoology, D.A.V. (P.G.) College, Dehradun-248001, INDIA \\ *Corresponding author. E-mail: sunilkumarddn@yahoo.co.in
}

Abstract: The purpose of this study was to know the hepatotoxicity of ethanol in laboratory rats Rattus rattus and to observe the individual and combined phytotherapeutic role of five herbs viz. Arctium lappa, Curcuma longa, Piper longum, Plumbago zeylanica and Terminalia chebula through biochemical and histopathological parameters. Ethanol is commonly used as solvent, pharmaceutical, drugs and alcohol abuse. Lipidperoxidation, glutathione content, urinary hydroxyproline, collagen and histopathological studies showed hepatotoxicity of $1 \mathrm{ml} / \mathrm{kg}$ body weight dose of ethanol and protective role of $100 \mathrm{mg} / \mathrm{kg}$ body weight dose of herbs. Histopathological changes observed in the liver of rats after ethanol treatment showed hepatitis, collagenesis, fatty infiltration, sclerosis, perilobular necrosis, cytoplasmic degeneration, enlarged bile canaliculi, hydropic degeneration, focal necrosis, binucleated hepatocytes and nuclear degeneration. Mild cytoplasmic degeneration, necrosis, collagenesis and hepatocytes regenerations were observed in rats treated with same dose of ethanol and herbal combination. Ethanol treatment decreased the glutathione content, increased tissue malondialdehyde and collagen content, thus causing tissue injury and liver collagenesis. Urinary hydroxyproline level and biochemical parameters also showed the protective role of herbs against ethanol induced toxicity. Herbal combination i. e. $100 \mathrm{ml} / \mathrm{kg}$ body weight from the mixture of five herbs given orally was found more effective than their individual role. Herbs and plants contain aromatic substances, secondary metabolites, alkaloids and polyphenols which act as antioxidant thus showing protective role.

Keywords: Hepatotoxicity, Histopathology, Ethanol, Herbal Combination, Antioxidant

\section{INTRODUCTION}

Medicinal plants are natural resources and their use in the regulation of chemical induced toxic effects has gained more impetus in recent years. The plants and herbal medicines used generally known as the Rasayan drug in Ayurveda are known to prevent ageing, increase longevity and resistance to disease by augmenting the immune system and quenching the free radicals. Free radicals are generated in the body during normal cellular processes like stress, environment toxins, smoking, alcohol, drugs, pollutants and radiations. Free radicals induced damage accumulates with age. Oxidative stress has been shown to be involved in the development and pathogenesis of hypertension, diabetes, arthritis, aging, immune inflammatory disorders and neurodegenerative disorders (Ammon and Wahl, 1994).

The metabolism of most xenobiotics takes place in the liver, which makes this organ very vulnerable to numerous chemical substances present in the environment (Le Blanc, 1994). Chronic ethanol consumption causes injury to almost all organ systems including liver and gastro-intestine and has serious medical and public health implications. Oxidative damage to lipid, protein and DNA after ethanol intoxication of the liver is very well described (Nordmann et al., 1992). It has further been observed that most of the consumed alcohol is eventually broken down by the liver and the products generated and accumulated during alcohol metabolism are more toxic than alcohol itself (Kurose et al., 1996). Therapeutic tools to control or reverse the ethanol induced cellular damages, such as alcoholic liver injury, are also lacking. In addition to its direct actions, ethanol induced effects are also mediated by oxidative e.g. acetaldehyde reactive oxygen species (ROS) and nonoxidative e.g. phosphatidyl ethanol, fatty acid ethyl ester, metabolites/ products and impairments in the methylation process. It is the combination of metabolic stress path ways, termed as "ethanol metabolic stress", which contributes to the epigenetic effect of ethanol (Shukla and Aroor, 2006).

Arctium lappa and Curcuma longa have antiinflammatory and free radical scavenging activities ( Lin et al., 2002). Piper longum Indian long piper commonly called "Pippali". Its principal constituents are piperine and piplartine. Plumbago zeylanica commonly known as "Chitrak" is a useful Indian medicinal plant, its constituents are credited with potential therapeutic properties, including anti-atherogenic, cardiotonic and hepatoprotective and neuroprotective properties. Terminalia chebula is useful in asthma, piles, bile trouble, burn, bleeding, blood pressure, cooling wash of the eyes, 
cough, dysentry and vomiting. Use and search for drugs and dietary supplement derived from plants have accelerated now days (Chopra et al., 1992 and Yuen et al., 2006). Terminalia chebula (Haritaki) is known to have extraordinary powers of healing with a wide spectrum of biological activity (Chattopadhyay and Bhattacharyya, 2008). Thus, a study has been undertaken with the objective to observe the individuals and combined role of certain herbs against ethanol induced liver injury in rats.

\section{MATERIALS AND METHODS}

Forty male laboratory bred rats Rattus rattus (albino) $(150 \pm 20 \mathrm{~g})$ were divided into eight groups at random, each containing five rats. Each rat was housed individually and feed on commercial pellets and kept in laboratory conditions (room temp. $25 \pm 5^{\circ} \mathrm{C}$, relative humidity $60 \pm 10 \%$ ). After acclimatization to laboratory conditions, rats were treated with sub lethal dose of ethanol. Group I was kept as control. Group II was treated with ethanol $1 \mathrm{ml} / \mathrm{kg}$ / body weight i.e. $0.15 \mathrm{ml}$ each rat orally on alternate days. Group III was treated with ethanol + Arctium lappa, Group IV was treated with ethanol + Curcuma longa, Group V was treated with ethanol + Piper longum, Group VI was treated with ethanol + Plumbago zeylanica. Group VII was treated with ethanol + Terminalia chebula and finally Group VIII was treated with ethanol + herbal combination. Herbs were given in powder form orally on every day with the dose of $100 \mathrm{mg} / \mathrm{kg}$ body weight i. e. $15 \mathrm{mg}$ each rat. Herbal complex was prepared by mixing the equal amount of five herbs and given $15 \mathrm{mg}$ of this combination to each rat. Herbs were collected from local field and Dehradun market. Treatment was given for thirty days.

After completion of treatment on thirty first day rats were sacrificed by using ether anesthesia. Liver was collected and homogenate was prepared with $0.9 \%$ sodium chloride. Lipid peroxidation in liver was measured by thiobarbituric acid (Wako, Japan) method (Smith and Anderson, 1987). Reduced glutathione (GSH) was estimated in the liver by following the method of Ellman (1959) using dithiobisnitrobenzoic acid. Oxidised glutathione (GSSG) was estimated in the liver following the method of Ohmori et al. (1981). Liver collagen was extracted from dried liver sample by the method suggested (Fitch et al., 1955) using $30 \%$ trichloroacetic acid. Hydroxyproline a reliable marker of collagen metabolism was estimated in urine samples using colorimetric method of Pondenphent et al. (1984). Histopathology of liver was performed through hematoxylin- eosin stain. Values reported are mean and standard error and inter group comparisons were made using students't test (Fisher, 1950).

\section{RESULTS AND DISCUSSION}

Results on liver lipid peroxidation, collagen and glutathione after ethanol treatment individually and with the combination of herbal complex indicated that the level of lipid per oxidation and collagen increased and the level of glutathione decrease in all the treated rats. An increase in liver collagen and urinary hydroxyproline level was reported after ethanol treatment. Individual and combination of herbs with ethanol decreased the collagen and hydroxyproline level in comparison to ethanol treatment. Treatment of herbal complex gave more protection in comparison to individual herbal treatment in ethanol treated rats. A non significant decrease in glutathione level in ethanol co-treated with herbal combination was observed indicating its protective role (Tables 1 and 2). Treatment of ethanol caused hepatic dysfunction and collagenesis. Ethanol administration promoted hepatic fibrosis, collagenesis, necrosis, cytoplasmic degeneration and fatty infiltration. Fatty infiltration is the most common pathological manifestation studied in a number of laboratory animals after exposure to ethanol leading to severe histological lesions viz. hepatitis, fibrosis, necrosis and cirrhosis (Ronis et al., 2004). Pathological changes were less severe in rats cotreated with herbs and showed hepatocyties regeneration (Table 3, Figs.1-8).

The present results are supported by the studies that the herbs significantly preserve the level of glutathione,

Table 1. Malondialdehyde, reduced glutathione and oxidized glutathione content in liver of rats treated with ethanol and with herbal complex.

\begin{tabular}{|c|c|c|c|c|}
\hline S. No. & Treatment & $\begin{array}{c}\text { M alondialdehyde } \\
\text { (nano.mol e/mg protein) }\end{array}$ & $\begin{array}{l}\text { Reduced glutathione } \\
\text { (mg/g of tissue) }\end{array}$ & $\begin{array}{c}\text { Oxidized glutathione } \\
\text { ( } \mu \mathrm{g} / \mathrm{g} \text { L iver) }\end{array}$ \\
\hline 1. & Control & $132 \pm 4.20$ & $1480 \pm 11.62$ & $410 \pm 6.78$ \\
\hline 2. & Ethanol & $275 \pm 5.18 * *$ & $1200 \pm 13.60 * *$ & $340 \pm 8.10 * *$ \\
\hline 3. & Ethanol + Arctium lappa & $270 \pm 0.90^{*}$ & $1275 \pm 10.09 * *$ & $357 \pm 8.04 *$ \\
\hline 4. & Ethanol + Curcuma longa & $268 \pm 4.12 *$ & $1315 \pm 8.01 *$ & $370 \pm 3.01^{*}$ \\
\hline 5. & Ethanol + Piper longum & $260 \pm 2.31^{*}$ & $1339 \pm 3.67 *$ & $363 \pm 1.20^{*}$ \\
\hline 6. & Ethanol + Plumbago zeylanica & $271 \pm 1.18^{*}$ & $1200 \pm 1.03 *$ & $344 \pm 1.11^{*}$ \\
\hline 7. & Ethanol + Terminalia chebula & $270 \pm 2.21^{*}$ & $1252 \pm 2.03 *$ & $362 \pm 0.01 *$ \\
\hline 8. & Ethanol + Herbal complex & $245 \pm 2.28 *$ & $1357 \pm 7.40 *$ & $391 \pm 6.68^{*}$ \\
\hline
\end{tabular}

Results are mean \pm S.E. of 5 observations in each group of rats. $\mathrm{P}=<* 0.1, * * 0.05$ (between control and experimental rats). 


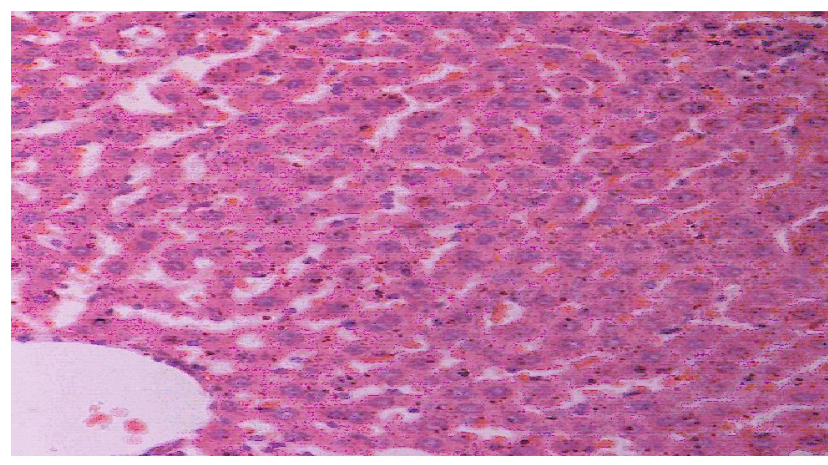

Fig. 1. T. S. of liver of control rat showing normal hepatocytes and portal canal.

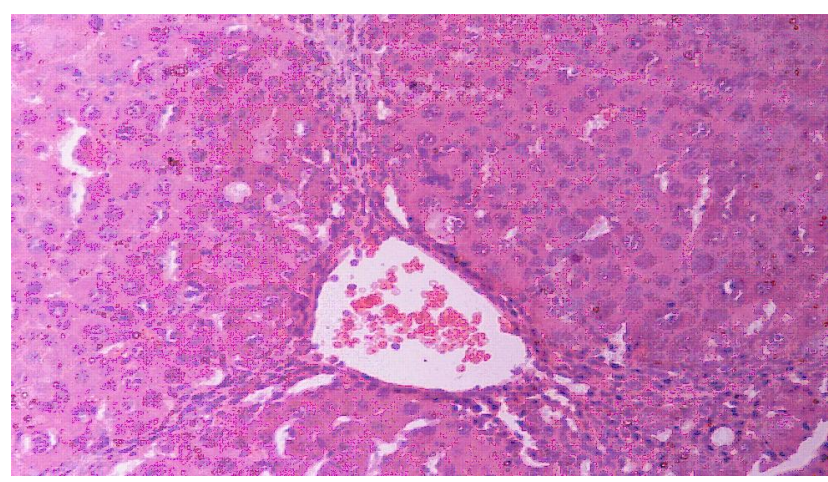

Fig. 2. T. S. of liver of rat treated with ethanol showing hepatitis, hemorrhage, necrosis, sclerosis and nuclear degeneration.

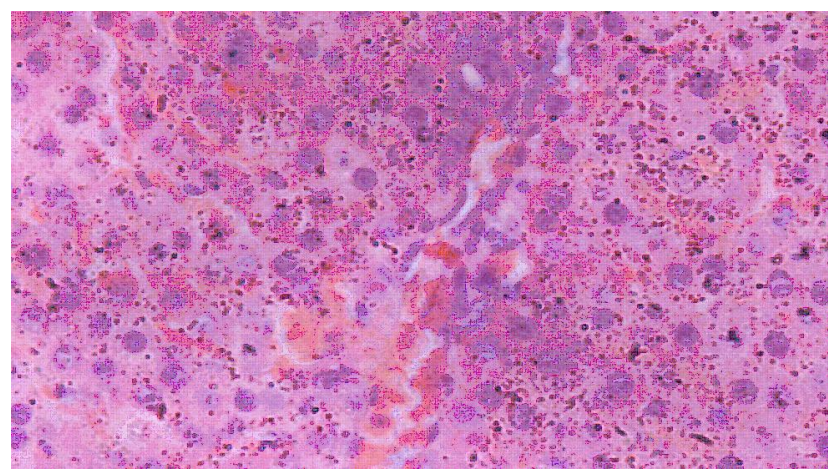

Fig. 3. T. S. of liver of rat treatced with ethanol and A. Iappa showing cytol pasmic degeneration and necrosis.

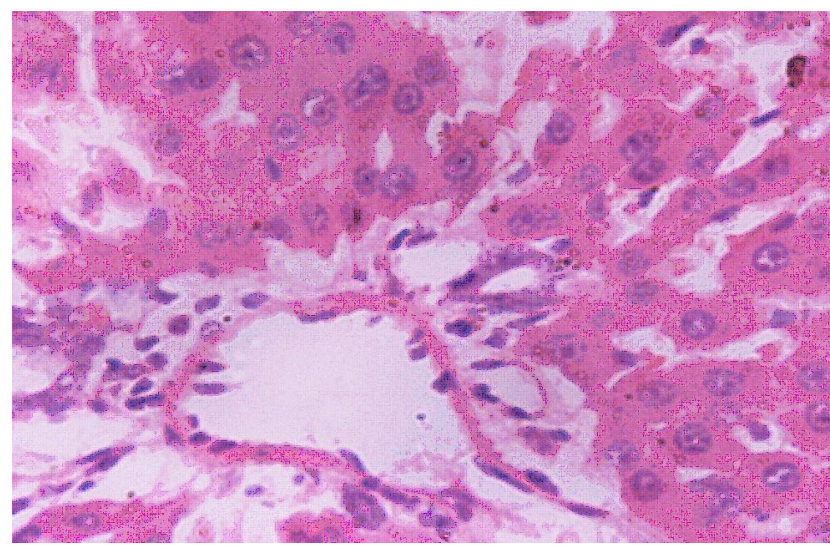

Fig. 4. T. S. of liver of rat treated with ethanol and C. Ionga showing collagenesis and degeneration.

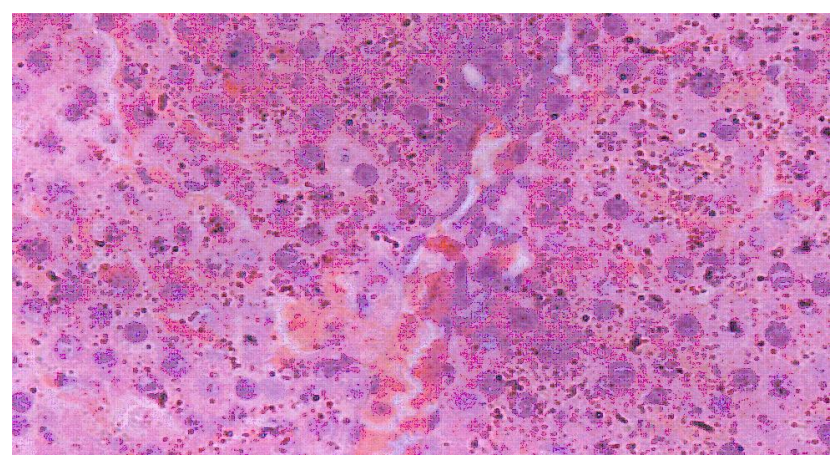

Fig. 5. T. S. of liver of rat treated with ethanol and P. Iongum showing degeneration and sclerosis.

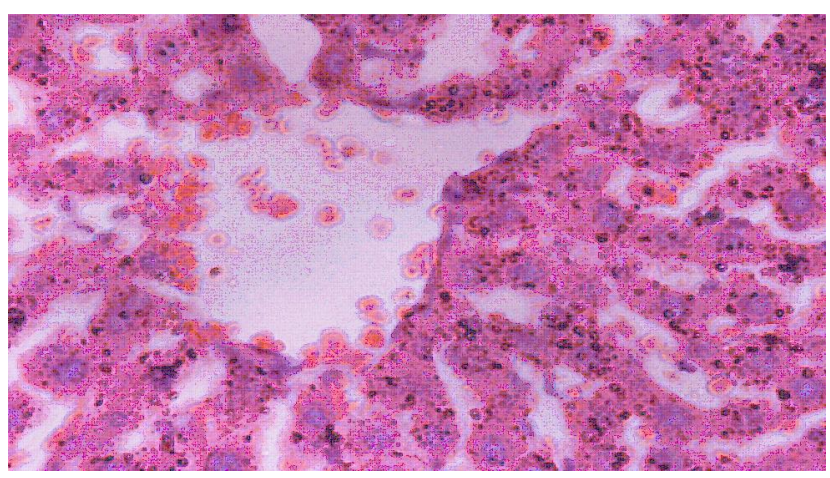

Fig. 6. T. S. of liver of rat treated with ethanol and P. zeylanica showing hemorrhage, fatty infiltration with portal and cytoplasmic degeneration.

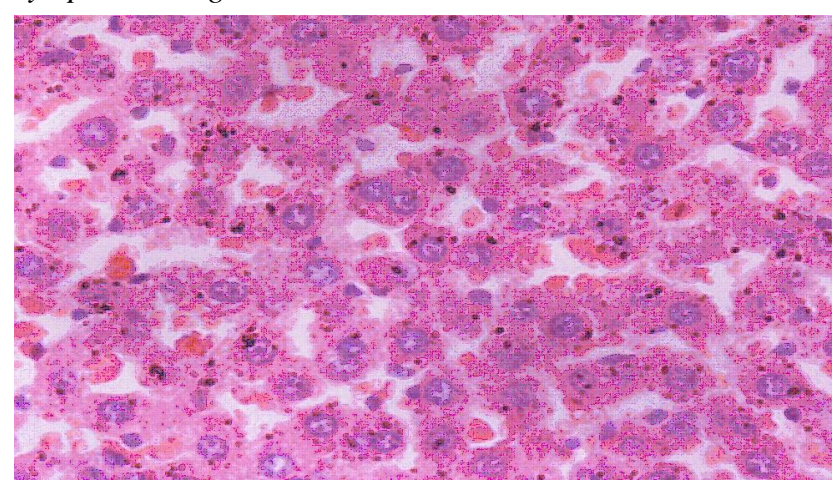

Fig. 7. T. S. of liver of rat treated with ethanol and T. chebula showing degener ation and necrosis.

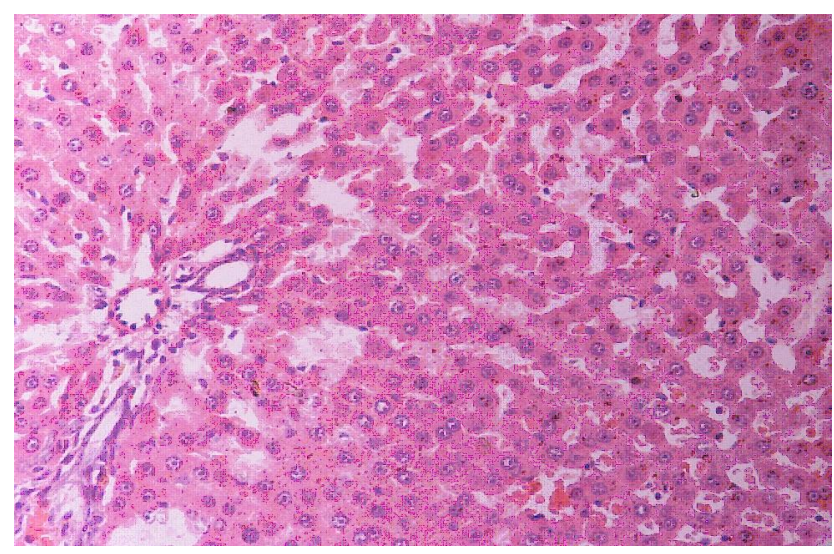

Fig. 8. T. S. of liver of rat treated with ethanol and herbal complex showing regeneration of hepatocytes and mild cytoplasmic degeneration. 
Table 2. Collagen and urinary hydroxyproline content in liver of rats treated with ethanol and with herbal complex.

\begin{tabular}{llcc}
\hline S. No. & Treatment & Collagen level $(\mathrm{mg} / 100 \mathrm{gm})$ & Urinary hydroxyproline $(\mu \mathrm{g} / 24$ hours $)$ \\
\hline 1. & Control & $42 \pm 0.29$ & $14 \pm 2.10$ \\
2. & Ethanol & $68 \pm 1.17^{*}$ & $33 \pm 0.80^{* *}$ \\
3. & Ethanol + Arctium lappa & $60.3 \pm 0.16^{*}$ & $28 \pm 0.80^{*}$ \\
4. & Ethanol + Curcuma longa & $61.4 \pm 0.22^{*}$ & $30 \pm 0.80^{*}$ \\
5. & Ethanol + Piper longum & $62 \pm 0.10^{*}$ & $29 \pm 2.01^{*}$ \\
6. & Ethanol + Plumbago zeylanica & $58 \pm 1.40^{*}$ & $30 \pm 0.80^{*}$ \\
7. & Ethanol + Terminalia chebula & $62 \pm 2.15^{*}$ & $27 \pm 1.80^{*}$ \\
8. & Ethanol + Herbal complex & $55 \pm 1.24^{*}$ & $24 \pm 0.20^{*}$ \\
\hline
\end{tabular}

Results are mean \pm S.E. of 5 observations in each group of rats. $\mathrm{P}=<* 0.1, * * 0.05$.

in the ethanol injured rat hepatocytes (Kim and Shukla, 2005; Perez et al., 2003). Toxic effect of ethanol is due to free radical generation, causing lipid peroxidation thus altering the permeability of the liver cell membranes. It causes liver necrosis in dose dependent manner in vivo (Johnston and Kroening, 1998).Wang et al. (2009) states that the presence of ethanol in combination with hypoxia causes greater cellular damage as compared to conditions of ethanol or hypoxia alone. Clinical studies demonstrated that both the apoptotic index and proliferating cell numbers were higher in patients with chronic alcoholic disease than controls (Farias et al., 2008). The mechanism of this protective effect of herbal combination remains to be elucidated. Herbs restore the antioxidant level and quench the oxidative radicals and give protection. Herbal complex treatment further shows the protective role.
Protective effect of burdock (Arctium lappa) on oxidation of low-density fat and stress in macrophages is known (Wang et al., 2006). A. lappa could protect the cell from ethanol induced liver damage with the same mechanism (Song et al., 2003). Plumbago zeylanica is useful Indian medicinal plant and its cardiologic, hepatoprotective and neuroprotective effect has been reported (Tilak et al., 2004). Piperine is an active principle of piper longum and is known for its hepatoprotective and antioxidative properties as well as its ability to enhance the bioavailability and therapeutic effectiveness of various agents (Khajuria et al., 1998; Nirala et al., 2007). Terminalia chebula also protected the human lymphocytes from undergoing the gamma radiation induced damage to DNA exposed in vitro (Gandhi and Nayar, 2005). Protective effect of T. chebula fruit on the

Table 3. Histopathological changes in liver of rats treated with ethanol and herbs individually and with herbal complex.

\begin{tabular}{|c|c|c|c|c|c|c|c|c|}
\hline Observations & Control & Ethanol & $\begin{array}{l}\text { Eth+A. } \\
\text { Lappa }\end{array}$ & $\begin{array}{c}\text { Eth+C. } \\
\text { Ionga }\end{array}$ & $\begin{array}{l}\text { Eth+P. } \\
\text { longum }\end{array}$ & $\begin{array}{c}\text { Eth+P. } \\
\text { zeylanica }\end{array}$ & $\begin{array}{l}\text { Eth+T. } \\
\text { chebula. }\end{array}$ & $\begin{array}{l}\text { Eth+Herb } \\
\text { al complex }\end{array}$ \\
\hline Binucleated cells & Rare & + & + & + & + & + & + & + \\
\hline Centrilobular necrosis & - & + & ++ & ++ & + & + & + & + \\
\hline Collagenesis & - & ++ & +++ & +++ & ++ & ++ & ++ & + \\
\hline Sclerosis & - & ++ & ++ & ++ & + & ++ & + & + \\
\hline Perilobular necrosis & - & + & ++ & + & + & + & + & + \\
\hline Fibrosis & - & ++ & +++ & ++ & ++ & ++ & + & + \\
\hline Cytoplasmic degeneration & - & ++ & ++ & ++ & + & + & + & + \\
\hline Multinucleated cells & - & ++ & + & + & + & ++ & + & + \\
\hline Hydropic degeneration & - & ++ & +++ & +++ & ++ & ++ & ++ & ++ \\
\hline Hepatitis & - & +++ & ++ & + & ++ & + & ++ & + \\
\hline Lipofuschin granules & + & ++ & + & + & ++ & ++ & + & + \\
\hline Increased cell volume & - & ++ & + & + & ++ & ++ & + & + \\
\hline Nuclear degeneration & - & + & ++ & + & ++ & + & + & + \\
\hline Kupfer cell hyperplasia & - & + & + & + & + & + & + & + \\
\hline Fatty infiltration & - & ++ & ++ & ++ & + & ++ & + & + \\
\hline Periportal inflammation & + & ++ & ++ & + & + & ++ & ++ & + \\
\hline
\end{tabular}

$(+)=$ Mildly Present, $(++)=$ moderately present, $(+++)=$ markedly present and $(-)=$ absent. 
tert-butyl hydroperoxide induced oxidative injury observed in cultured rat primary hepatocytes and rat liver (Lee et al., 2007). Results are supported by the previous studies on enzymological changes through herbs against chemical induced toxicity in rats (Kumar et al., 2009).

\section{Conclusion}

Ethanol treatment causes hepatitis and collagenesis by decreasing glutathione content and increasing malondialdehyde level, which cause lipidperoxidation leading to liver injury. Combination of herbs was found more effective than their individual role. Herbs and plants contain aromatic substances, secondary metabolites, alkaloids, glutathione, flavanoids and polyphenols, which acts as antioxidants and quench the oxidative radicals.

\section{REFERENCES}

Ammon, H.P.T. and Wahl, M.A. (1994). Pharmacology of Curcuma longa. Planta Med., 57: 1-5.

Chopra, R.N., Nayer, S.L. and Chopra I.C. (1992). Glossary of Indian medicinal plants, $3^{\text {rd }}$ Edn. New Delhi: Council of Scientific and Industrial Research, 7: 246- 52.

Chattopadhyay, R.R and Bhattacharyya, S.K. (2008). Plant review: An Updated. Pharmacognosy Review, 1: 151-156.

Ellman, G.I. (1959). Tissue sulphahydril group. Arch. Biol. Chem. Bio. Phy., 82: 70- 73.

Farias, C.R., Santillan, E.M., Ceruelos, A.H., Gonzalez, J.A.M., Salinas, J.G., Sanchez, N.R., Cruz, M.M., Jones, I.V. and Martinez, I.G. (2008). Protective effect of some vitamins against the toxic action of ethanol on liver regeneration induced hepatectomy in rat. World J. Gastroenterol, 6: 14- 19.

Fisher, R.A. (1963). Statistical methods for research workers. Oliver and Boyd, London, 14: 119- 193.

Fitch, S. M., Harness, M. L. and Harness, R. D. (1955). Nature 163: 4473 - 4476.

Gandhi, N. M. and Nayar, C. K. K. (2005). Radiation protection by Terminalia chebula some mechanistic aspects. M olecular and C ellular Biochemistry, 277: 43-47.

Johnston, D.E. and Kroening, C. (1998). Mechanism of early $\mathrm{Ccl}_{4}$ toxicity in cultured rat hepatocytes, Pharmacol Toxicol, 83: 231 - 237.

Khajuria, A., Zutshi, U. and Bedi, K.L. (1998). Permiability characteristics of piperine an oral absorption -an active alkaloid from pippers and bioavailability enhancer. Indian J Expe. Biol., 36: 46-49.

Kim, J.S. and Sukla, S.D. (2005). Acute in vivo effect of ethanol on histone $\mathrm{H}_{3}$ modification in rat tissues. Alcohol Alcohol, 41: $126-132$.

Kumar, S., Devi, S. and Kumari, P. (2009). Biochemical and Enzymological changes in rats by herbal complex treatment against ethanol induced toxicity. J .Ecophysiol. Occup. Health, 9: 43 - 46.

Kurose, I., Higuchi, H., Kato, S., Miura, S. and Ishii, H. (1996). Ethanol-induced oxidative stress in the liver. Alcohol Clin Exp Res., 20: 77 - 81.

Lee, H.S., Jung, S.H., Yun, B.S. and Lee, K.W. (2007). Isolation of chebulic acid from Terminalia chebula and its oxidant effect in isolated rat hepatocytes. Arch Toxicol., 81: $211-216$.

Le Blanc, E. (1994). Hepatic victorial transport of xenobiotics. Chem Biol Inter act., 90: 101.

Lin, S.C., Lin, C.H., Lin, C.C., Lin, Y.H., Chen, C.E., Chen, C. and Wang, L.Y. (2002).Hepatoprotective effect of Arctium lappa linne on liver injuries induced by chronic ethanol consumption and potentiated by carbon tetra chloride. J of Biomedic Scie., 9: 5-9.

Nirala, S.K., Bhadauria, M. and Shukla, S. (2007). Durationdependent hepatoprotective effect of propolis extract against carbon tetra chloride-induced acute liver damage in rats. Advances in Therapy, 24: 1136- 1140.

Nordmann, R., Ribiere, C. and Rouach, H. (1992). Implication of free radical mechanisms in ethanol induced cellular injury. Free Rad Biol and M edic., 12: 219- 222.

Ohmori, S., Ikedo, M., Kasahara, E., Hyodoh, H., and Hiroto, K. (1981). A colorimetric determination of total glutathione based on its C-termination glycine residue and its application to blood, liver and yeast. Chem. Chem. Pharma. Bull., 29: 1355- 1360.

Perez, T.G., Ramos, G.C., Martinez, S.B., Giuliani, A. and Martinez, S.G. (2003). Protective effect of Gossypitrin on carbon tetra chloride-induced in vivo hepatotoxicity. Radox Report, 8: 215- 219.

Pondenphent, J., Larsen, N.E. and Christiansen, C. (1984). An easy and reliable method for determination of urinary hydroxyproline. Clinca C hem Acta., 142- 145.

Ronis, M.J.J., Korourian, S., Zipperman, M., Hakkak, R. and Badger, T. M. (2004). Dietry saturated fat reduced alcoholic hepatotoxicity in rats by altering fatty acid metabolism and membrane composition. Am. SoC. N utri. 904- 910.

Shukla, S.D. and Aroor, A.R. (2006). Epigenetic effect of ethanol on liver and gastrointestinal injury. World J of Gastr ointerol, 12: 5265- 5270.

Smith, C.V. and Anderson, R.E. (1987). Method for determination of lipid peroxidation in biological samples. Free Rad. Biol. M ed., 3: 341- 347.

Song, E.K., Cho, H. and Kim, J.S. (2003). Diarylheptanoids with free radical scavenging and hepatoprotective activity in vitro from Curcuma longa. Planta Med., 67: 876 - 880.

Srinivas, L. and Shalini, V.K. (1991). DNA damage by smoke: protection by turmeric and other inhibitors of ROS. Free Radical Biol Med., 11: 277-282.

Tilak J.C., Abhikari S. and Thomas P.A.D. (2004). Antioxidative property of Plumbago zylanica, an Indian medicinal plant and its activity ingredient, Plumbagin. Redox Report., 9: 219 - 225.

Wang, S.M. and Wu, R. (2009). The Double Danger of Ethanol and Hypoxia: Their Effects on a Hepatomas Cell Line. Int J Clin Exp Pathol., 2: 182-189.

Wang, B.S., Yen, GC., Chang, L.W., Yen, W.J. and Duh, P.D. (2006). Protective effect of burdock (Arctium lappa linne) on oxidation of low density lipoprotein and oxidative stress in RAW 264.7 macrophages., J Food Chemistry, 101: 729- 736.

Yuen, M.F., Tam, S. and Fung, J. (2006). Traditional Chinese medicine causing hepatotoxicity in patients with chronic hepatitis B infection: a 1-year prospective study. Ailment Pharmacol Ther., 24: 1179- 1187. 